\title{
Simulation Modeling of Dual Warehouse System
}

\section{Cynthia Candradewi ${ }^{1}$, Yu-Siang Linn ${ }^{1}$, Kung-Jeng Wang ${ }^{1}$, and | Gede Agus Widyadana²}

${ }^{1}$ Industrial Management Department, National Taiwan University of Science and Technology, Da'an District, Taipei 106, Taiwan

${ }^{2}$ Industrial Engineering Deppartmen, Universitas Kristen Petra, Jl. Siwalankerto no.121-131, Surabaya 60236, Jawa Timur, Indonesia

\section{Abstract}

Warehouse space allocation is a critical issue to be addressed in many firms, especially firms that have various types of products. Further, most of the owned warehouse has a limited capacity which leads to the usage of outsourcing policy for warehouse storage. In this case, a rented warehouse that has more flexibility in terms of capacity is used to store the products. Therefore, an optimal decision of warehouse configuration is required. The previous study proposed a two-stage stochastic optimization model for

Corresponding Author: Gede Agus Widyadana gede@petra.ac.id

Received: 16 February 2020 Accepted: 5 March 2020 Published: 10 March 2020

Publishing services provided by Knowledge E

(c) Cynthia Candradewi et al. This article is distributed under the terms of the Creative Commons Attribution License, which permits unrestricted use and redistribution provided that the original author and source are credited

Selection and Peer-review under the responsibility of the ICLBI (2018) Conference Committee. warehouse configuration and inventory policy for deteriorating items. Unfortunately, direct implementation of their proposed method in real case problem will incur high cost and takes up a lot of time. In this research, a simulation model is developed to monitor the real condition in the company as well as to ensure that the warehouse configuration is suitable to be implemented. A textile and apparel company is used as the study case. The result shows that simulation model can be used to monitor the real condition as well as to obtain the net profit when facing different demand possibility.

Keywords: Inventory control; real-time monitoring; system simulation; warehouse configuration; warehouse space allocation.

\section{Introduction}

Firms that have various types of products consider space allocation as a critical issue to be addressed. Since products may have different sizes and quantities, the product will need different space sizes for storing. Some of the products may also have higher inventory turnover than the others. For instance, in a retail company such as Hypermarkets, the product may vary from daily necessities with high inventory turnover to electronics product with low inventory turnover. The shelf arrangement for these products may affect the number of sales, as well as the utilization of the available space. Further, the products allocation in the warehouse may affect the agility of the 
company to replenish the products on the shelves. Therefore, an optimal decision of space allocation is needed.

In addition, most of the owned warehouse (OW) has a limited capacity which leads to the usage of outsourcing policy for warehouse storage. In this case, a rented warehouse (RW) that has more flexibility in terms of capacity is used to store the product. For instance, the consignment activity that can be found in a retail company, such as Hypermarket. Most of the shelves in the Hypermarket are rented by another firm that manufacture the products. This practice allows those firms to cope with the limited capacity in the OW, as well as achieves agility through the use of storage that locates near the end customers. Since the usage of outsourcing policy for warehouse storage will give an additional cost to the firms, an optimal decision of warehouse configuration is required.

A hybrid solution algorithm is suggested to select the warehouse location-allocation and configuration [1]. In their research, a two-stage decision-making model for selecting the warehouse location and configuration for serving multiple markets against stochastic demand, and for deriving an inventory policy for managing deteriorating items is developed. Their model considers price-sensitive demand and incentive policy in the fee of RW. The RW fee decreases over time to encourage a long-term partnership between the owner of the RW and the tenant. The objective of their research is to maximize the total profit of the entire system for managing stochastic demand and deteriorating items. The proposed method in their study can be used to solve the addressed problem. Unfortunately, direct implementation of the proposed method in real case problem is challenging to be conducted, as it will incur high computational cost and time. Thus, simulation model can be used to monitor the real condition in the company as well as to ensure that the warehouse configuration is suitable to be implemented.

The rest of the paper is organized as follows. Related literature review and previous works are discussed in Section 2. Section 3 provides the model formulation, as well as the proposed solution method. Section 4 provides the experiment results and analysis. The conclusion, summary of the research, and suggestions for the future research are provided in Section 5.

\section{Literature review}




\subsection{Outsource policy for warehouse storage}

Due to limited spaces that are available in the owned warehouse, outsource policy for warehouse storage is often used to cope with the limitation of the spaces. RW which has more flexibility in terms of capacity is used to store excess inventory. Several studies have been conducted to analyze the usage of outsource policy for warehouse storage. Liao et al. [2] consider deterministic order level for deteriorating items with finite warehouse capacity for the OW and trade credit for the RW. According to their result, the order quantity should be increased if the demand, as well as the available space in the OW increase. Lin and Wang [1] develop a two-stage model to determine the warehouse configuration for serving multiple markets against stochastic demand. Their model considers the deteriorating items, decreasing value in RW fee and the flexible capacity of the RW. According to Hariga et al. [3], all of the supply chain (SC) members, in this case, the RW's owner and the tenant, will be benefited if the RW's owner provides a flexible capacity.

\subsection{Simulation model}

Several studies have been conducted to analyze the usage of simulation study to solve logistics problem. Fleisch and Tellkamp [4] studied the inventory inaccuracy using a simulation model to understand the impact of several factors on the inaccuracy. Huq et al. [5] used a simulation study to compare the usage of one warehouse and two warehouses to serve multiple customers, and concluded that the usage of two warehouses reduces delivery lead times as the warehouse is closer to the customer. Tako and Robinson [6] reviewed several studies related to the use of discrete event simulation and system dynamics to solve a problem in logistics and SC. According to their study, discrete event simulation is used more frequently than system dynamics to model an SC.

Longo and Mirabelli [7] developed a flexible, time-efficient SC simulator using a discrete event simulation and also an analysis of the usage of DOE and ANOVA to evaluate the result. They suggested using DOE and ANOVA, as the ANOVA results provide input-output analytical relations to help find the optimal strategy selection. Ramanathan [8] studied the performance of SC collaboration using simulation. Since all SC processes need to be evaluated from time to time to analyze the performance of the SC collaboration, a simulation study is used as it will cost less than establishing the actual collaboration. 


\subsection{Summary}

In summary, the simulation model can be used to analyze the problem in various areas, including warehouse allocation. In terms of the limited capacity of the owned warehouse, the usage of two warehouses can be used to solve the problem and two-stage model which is proposed in 0 can be utilized to determine the warehouse configuration. The proposed method can already be applied in real case problem, but further analysis when different demand value occurs is still needed. Furthermore, the usage of resources for material handling in the warehouses are also needed to be included into consideration.

\section{Model development}

\subsection{Model formulation}

This research extends the research by Lin and Wang [1]. A two-stage model is developed as mixed-integer nonlinear programming for location-allocation decision and inventory policy for deteriorating products. In the first stage, the decision of whether to use OW or RW for multiple markets is determined. If OW is decided to be established, then the capacity of the warehouse will be decided. If RW is decided to be utilized, then unlimited capacity is used in the warehouse and the decreasing value in RW fee will be considered. The decision in the first stage will also be influenced by the budget constraint and the price-sensitive demand. In the second stage, inventory policy for the related warehouse is determined. The inventory policy consists of replenishment quantity and replenishment cycle time. A conceptual framework of the two-stage model can be seen in Figure 1.

There are several assumptions that are considered in the model, explained as follows:

1. OW has limited storage capacity, while RW has unlimited storage capacity. A firm can use only OW, only RW or both in each market.

2. In terms when RW is used, the decreasing value in the rent warehouse fee is considered. The rent warehouse fee will exponentially decrease over storage time. Specifically, the rent warehouse fee will decrease by $u_{i} \%$ per unit of time between $t_{i}^{\min }$ and $t_{i}^{\max }$, where $t_{i}^{\min }$ is the least amount of storage time desired by the RW owner, and $t_{i}^{\max }$ is the amount of storage time reached by the rental [9].

3. The products can deteriorate, but the replacement of the deteriorated products are not considered [10]. 


\section{Two-Stage Stochastic Location-Allocation Inventory System}

Stage 1: Location and Warehouse Configuration Design

Determine the location of the warehouse and warehouse configuration

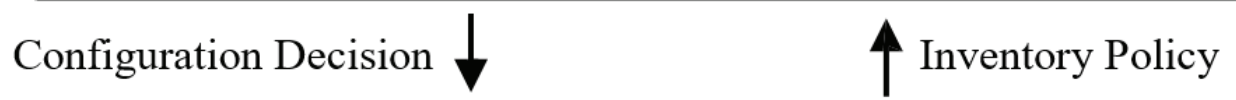

\section{Stage 2: Inventory Policy Design}

Customer with

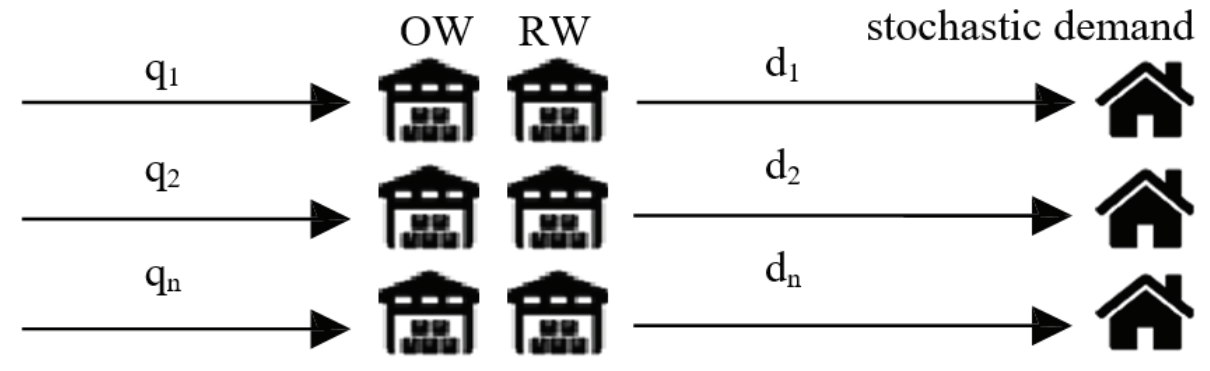

Figure 1: Conceptual research framework.

The mathematical model is based on the assumption that was mention before. The following notations of parameters and variables are introduced to formulate the problem.

\subsubsection{Parameters for the first stage}

$\rho_{i} \quad$ The unit sale price in market $\mathrm{i}, \mathrm{i}=\{1,2, \ldots, \mathrm{I}\}$ where $\mathrm{I}$ is the total number of candidate markets.

$D^{k} \quad$ A set of demand rate of markets in scenario $k, k=\{1,2, \ldots, K\}$ where $K$ is the total number of demand scenarios. $\mathrm{Dk}=\left\{d_{1}^{k}, d_{2}^{k}, \ldots, d_{i}^{k}\right\}$ where $d_{i}^{k}$ is the demand rate of market $i$ in scenario $k$. Assume the demand rates follow a probability distribution function as a parameter of $\rho_{i}$.

$\mathrm{B}\left(\mathrm{W}_{i}, \mathrm{~d}_{i}\right) \quad$ The average setup cost function in OW for market $\mathrm{i}$ with storage capacity $\mathrm{W}_{i}$ and demand $\mathrm{d}_{i}$.

$\mathrm{R}\left(\mathrm{d}_{i}\right) \quad$ The setup cost function in RW for market $\mathrm{i}$ with demand $\mathrm{d}_{i}$. BG, the total budget for overall setup cost of OWs and RWs.

ED The mathematical expectation with respect to demand state D. 


\subsubsection{Parameters for the second stage}

$\mathrm{O}_{i} \quad$ Ordering cost per order in market $\mathrm{i}$ (USD/ordering).

$\mathrm{b}_{i} \quad$ The unit administration cost of RW in market $\mathrm{i}$ (USD/unit/yr).

$\mathrm{H}_{O i} \quad$ The unit holding cost of OW in market i (USD/unit/yr).

$\mathrm{H}_{R i} \quad$ The unit holding cost of RW in market i (USD/unit/yr), $\mathrm{H}_{R i}>b_{i}$.

$\mathrm{P}_{i} \quad$ The unit deteriorating cost in market i (USDunit).

$\theta_{O i} \quad$ Deterioration rate of goods of OW in market i.

$\theta_{R i} \quad$ Deterioration rate of goods of RW in market $\mathrm{i}$.

U The unit purchasing price.

\subsubsection{Decision variables for the first stage}

$\mathrm{W}_{i} \quad$ Storage capacity of OW for market $\mathrm{i}$.

$\mathrm{x}_{i} \quad \mathrm{x}_{i}=1$ if an OW is built for market $\mathrm{i}$; otherwise $\mathrm{x}_{i}=0$.

$\mathrm{y}_{i} \quad \mathrm{y}_{i}=1$ if an RW is rented for market $\mathrm{i}$; otherwise $\mathrm{y}_{i}=0$.

$\left(\mathrm{x}_{i}, \mathrm{y}_{i}\right) \quad$ A pair notation of the warehouse configuration, as listed in Table 1.

TABLE 1: Warehouse configuration representation

$\begin{array}{ll}\left(\mathbf{x}_{i}, \mathbf{y}_{i}\right) & \text { Warehouse Configuration } \\ (0,0) & \begin{array}{l}\text { Setup no warehouse. Neither OW nor RW is setups in market } \mathrm{i}, \text { market } \mathrm{i} \text { is } \\ \text { abandoned }\end{array} \\ (0,1) & \text { Use RW only } \\ (1,0) & \text { Use OW only } \\ (1,1) & \text { Use both OW and RW }\end{array}$




\subsubsection{Decision variables for the second stage}

$\mathrm{q}_{i} \quad$ Ordering lot size for market i.

$\mathrm{t}_{O i} \quad$ Usage duration of OW for market i.

$\mathrm{t}_{R i} \quad$ Usage duration of RW for market $\mathrm{i}$.

$\mathrm{T}_{i} \quad$ Replenishment cycle time for market $\mathrm{i}$

Since $\mathrm{t}_{O i}, \mathrm{t}_{R i}$, and $\mathrm{T}_{i}$ are interdependent to $\mathrm{q}_{i}$, the inventory policy can be defined as $\mathrm{q}_{i}$.

In the first stage, the location and warehouse configuration is determined. The objective function Equation 1 is to maximize the expected profit of $\mathrm{K}$ demand scenarios. The decision whether to use OW or RW in each market and the storage capacity of the $\mathrm{OW}$ are made Equation 2. If $\mathrm{OW}$ with storage capacity $\mathrm{W}_{i}$ is decided to be established, setup cost $\mathrm{B}\left(\mathrm{W}_{i}, \mathrm{~d}_{i}\right)$ will be incurred. If $\mathrm{RW}$ is decided to be utilized, setup cost $\mathrm{R}\left(\mathrm{d}_{i}\right)$ will be incurred. The total setup cost will affect the decision of whether to use OW or RW in each market. In which, the total setup cost should be lower than the total budget BG Equation 3.

$$
\text { Minimize } E_{d}\left[\sum_{i=1}^{r} x_{i} B\left(W_{i}, d_{i}\right)+\sum_{i=1}^{r} y_{i} R\left(d_{i}\right)-L(x, y, W, D)\right]
$$

where $L(x, y, W, D)$ is the total profit provided by the second stage.

$$
\begin{gathered}
\text { Subject to } x_{i} \in\{0,1\}, y_{i} \in\{0,1\}, 0 \leq W_{i} \leq x_{i} d_{i} \\
\sum_{i=1} x_{i} B\left(W_{i}, d_{i}\right)+\sum_{i=1}^{r} y_{i} R\left(d_{i}\right) \leq B G
\end{gathered}
$$

In the second stage, the inventory policy for the related warehouse are decided. The inventory policy consists of replenishment quantity and cycle time. The objective function Equation 4 is to maximize the total profit of all market. This problem can be categorized as constrained nonlinear programming. The details of all the constraints refer to Lin \& Wang [1].

$$
L(x, y, W, D)=\sum_{i \in\left\{x_{i}=1 \text { or } y_{i}=1\right\}} \rho_{i} d_{i}-\frac{T C_{i}}{T_{i}}
$$




\subsection{Solution method}

The simulation model will be developed to implement the proposed method in Lin \& Wang [1] to solve a real-case problem. Therefore, to ensure the simulation model can imitate the proposed method well, verification and validation process are conducted after the simulation model is developed. Several parameters from the simulation result will be compared to the parameters from the theoretical result. In the verification process, the parameters that will be compared are the number of deteriorated products, replenishment quantity, replenishment cycle time, and the number of replenishment.

The system consists of 10 markets, which have a different number of demand. The demand in each market is dependent on the sale price of the product but independent to the demand of the other market. The products can be deteriorated and will not be sent to the customers, but will add deterioration cost for the company. In the validation process, the parameter that will be compared is the profit that is obtained in each market. The comparison is conducted for five times. In each comparison, the model uses a different demand scenario for each market (Table 2.). For each scenario, the number of demand for each market is sampled from $\log _{\text {normal }}\left(1000-2 \rho_{i}, 10^{2}\right)$ where sale price pi U(175 225).

TABLE 2: Demand scenario for each market

\begin{tabular}{|c|c|c|c|c|c|c|c|c|c|c|}
\hline Market & 1 & 2 & 3 & 4 & 5 & 6 & 7 & 8 & 9 & 10 \\
\hline Scenario 1 & 561 & 560 & 643 & 575 & 562 & 539 & 580 & 631 & 551 & 634 \\
\hline Scenario 2 & 569 & 553 & 636 & 570 & 573 & 572 & 592 & 637 & 569 & 625 \\
\hline Scenario 3 & 571 & 553 & 642 & 564 & 559 & 549 & 589 & 634 & 563 & 619 \\
\hline Scenario 4 & 548 & 559 & 650 & 553 & 557 & 537 & 607 & 647 & 559 & 631 \\
\hline Scenario 5 & 571 & 564 & 641 & 570 & 560 & 551 & 592 & 631 & 575 & 621 \\
\hline
\end{tabular}

In the addressed problem, some parameters such as RW fee as well as the inventory level are changing over time. Since the simulation model in this research will be created using Flexsim, which is a discrete-event simulation software [15], some parameters in the simulation model will be adjusted to cope with the software limitation.

\subsubsection{Assumptions for the simulation model}

Several assumptions are considered in the simulation model, explained as follows:

1. OW layout and corresponding transportation delay are considered. Millimetres is used as the units of length, and seconds is used as the units of time. 
2. The planning horizon is $1 \mathrm{~h}=3600 \mathrm{~s}$. Since the planning horizon in [1] is $1 \mathrm{yr}$ and the replenishment cycle time from the optimization result is $0 \leq T_{i} \leq 1$. The replenishment cycle time in the simulation model $\mathrm{T}_{S i}$ will be calculated as [ 3600 $\left.\times \mathrm{T}_{i}\right]$.

3. The number of markets that are used in the simulation model is 10 .

4. The demand is received every hour. In which shown in Equation 5, one product will be sent to the customer. The number of demand that is fulfilled in each replenishment cycle $\mathrm{T}_{S i}$ are calculated in Equation 6

$$
\begin{gathered}
t_{p}=\frac{t_{S i}}{\left[q_{i}\right]+\left[\frac{\left[q_{i}\right]}{T_{i}}-d_{i}\right]} \\
c_{i}=\left[d_{i} T_{i}\right]
\end{gathered}
$$

5. The number of deteriorated products in the planning horizon is calculated in Equation 7

$$
d p_{i}=\left[\frac{1}{T_{i}}\left(\left[q_{i}\right]-d_{i} T_{i}\right)\right]=\left[\frac{\left[q_{i}\right]}{T_{i}}-d_{i}\right]
$$

6. The first replenishment of all markets is conducted at time $\mathrm{T}_{S i}=1 \mathrm{~s}$.

7. The incentive policy of RW is ignored.

8. The simulation will be stopped when the demand in all markets are already fulfilled.

\subsubsection{Notations}

$\mathrm{n} \quad$ The number of replenishment in one planning horizon

$\mathrm{T}_{S i} \quad$ The replenishment cycle time in the simulation

tp The inter-arrival time of product in customer queue

$\mathrm{C}_{i} \quad$ The number of demand that is fulfilled in each replenishment cycle

$\mathrm{dp}_{i} \quad$ The number of deteriorated products in one planning horizon

$I_{O_{i}}^{m} \quad$ The inventory level of OW, where $I_{O_{i}}^{m}=\mathrm{m}$

$I_{R_{i}}^{m} \quad$ The inventory level of RW, where $I_{R_{i}}^{m}=\mathrm{m}$

$r_{i} \quad$ The remaining products in the warehouse at the end of the simulation

te ${ }_{O i} \quad$ The time when the inventory level in OW become equal to $r_{i}$

te ${ }_{R i} \quad$ The time when the inventory level in RW become equal to $r_{i}$ 


\subsubsection{Simulation model structure}

Each market consists of a supplier, an OW, an RW, and a customer (Figure 2). The product from the supplier will be sent to the warehouse in batch at time $\mathrm{T}_{S i}$, The number of products in one batch is the same as the ordering lot size $\mathrm{q}_{i}$. If $\mathrm{x}_{i}=1$, then OW will be used and the capacity of the OW is equal to $\mathrm{W}_{i}$. If $\mathrm{y}_{i}=1$, then RW will be used and the capacity of the RW is unlimited (assuming a large number of 109). Otherwise, the warehouse will not be used and the capacity of the related warehouse is equal to 0 . The product from the warehouse will be sent to the customer one by one. The deteriorated products will be sent to the deteriorate queue. The demand in each market is price sensitive with distribution $\log _{\text {normal }}(1000-2 p i, 102)$ where sale price $\rho i \sim U(175225)$. If the market demand is already satisfied, the warehouse will not be replenished and the net profit will be calculated. The parameter values that are used in the calculation can be seen in Table 3.

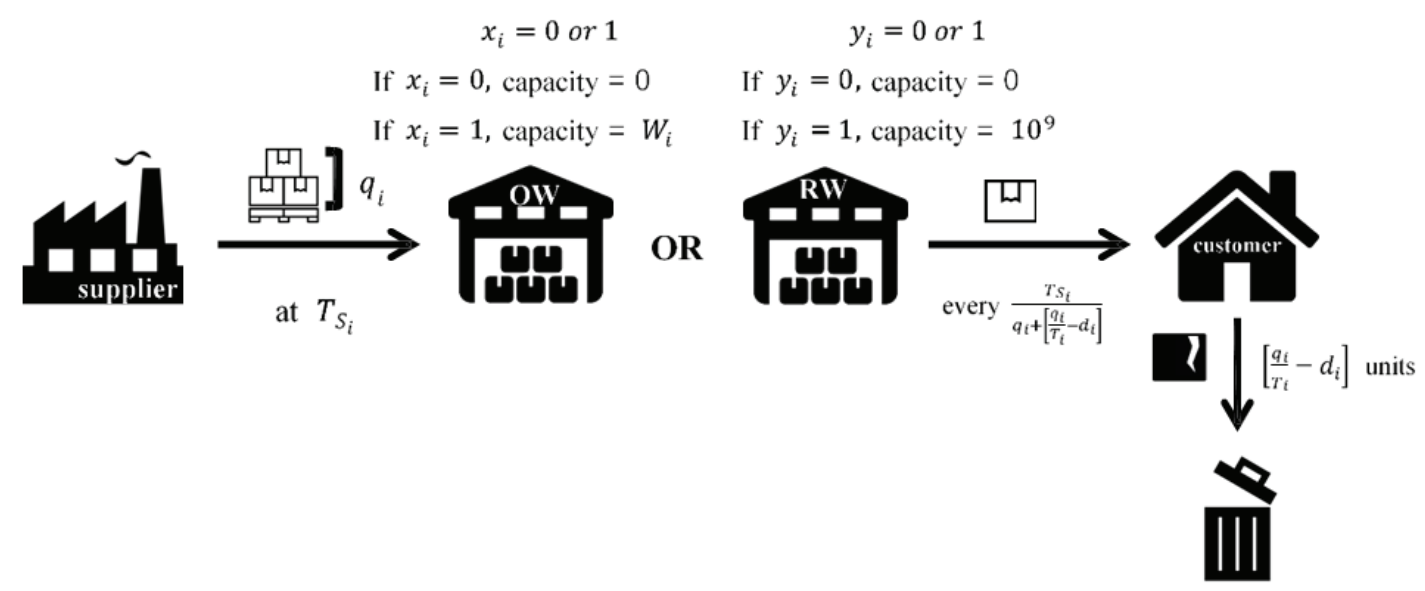

Figure 2: The framework of the simulation model.

\subsubsection{Verification process}

The verification process is conducted for five scenarios. In which, each scenario has a different number of demand for each market (Table 2). In the verification process, the number of deteriorated products, replenishment quantity, replenishment cycle time, and the number of replenishment that is obtained from theoretical result and simulation result is compared. The comparison shows that there is no difference between the theoretical result and the simulation result. In conclusion, the simulation model can already perform according to the framework. 
TABLE 3: Paramater settings

\begin{tabular}{|c|c|c|c|c|c|c|c|c|c|c|}
\hline \multirow[t]{2}{*}{ Parameter } & \multicolumn{10}{|c|}{ Market } \\
\hline & 1 & 2 & 3 & 4 & 5 & 6 & 7 & 8 & 9 & 10 \\
\hline pi & 216 & 219 & 181 & 216 & 216 & 222 & 200 & 183 & 220 & 187 \\
\hline $\mathrm{Oi}$ & 931 & 589 & 575 & 683 & 764 & 589 & 529 & 758 & 598 & 875 \\
\hline $\mathrm{HOi}$ & 9.9 & 8.6 & 8.6 & 8.9 & 8.9 & 9.8 & 9.5 & 8.9 & 8.4 & 8.4 \\
\hline $\mathrm{HRi}$ & 11.7 & 10.7 & 11.9 & 10.0 & 11.2 & 10.3 & 11.5 & 11 & 10.3 & 11.4 \\
\hline $\mathrm{Pi}$ & 106 & 98 & 103 & 94 & 92 & 97 & 103 & 110 & 107 & 103 \\
\hline$U$ & \multicolumn{10}{|l|}{40} \\
\hline $\mathrm{B}(\mathrm{Wi}, \mathrm{di})$ & \multicolumn{10}{|c|}{$15 W_{i}+10 d_{i}$} \\
\hline $\mathrm{R}(\mathrm{di})$ & \multicolumn{10}{|l|}{$10 \mathrm{~d}_{i}$} \\
\hline$B G$ & \multicolumn{10}{|c|}{1500000} \\
\hline
\end{tabular}

\subsubsection{Validation process}

The net profit from the theoretical result is calculated from Equation 1. Since the theoretical model can be categorized as continuous system and the software is discreteevent simulation software, several adjustments are made in the simulation model. The incentive policy of RW is ignored. Therefore, the inventory level when both OW and RW is used (a), only OW is used (b), and only RW is used (c) can be described as Figure 3.

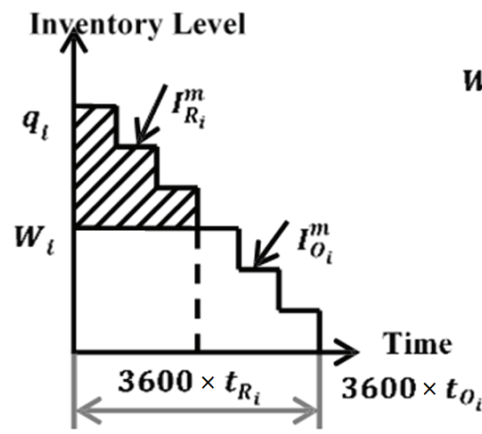

$T_{S_{i}}$

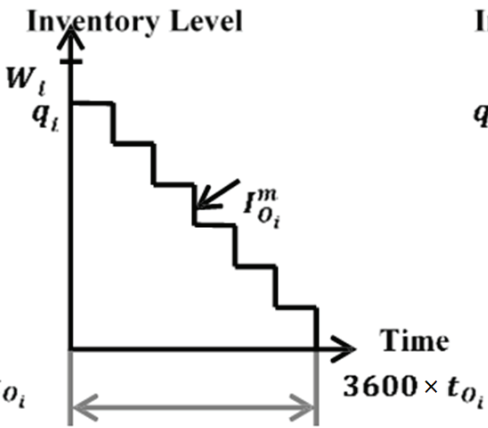

$T_{S_{j}}$

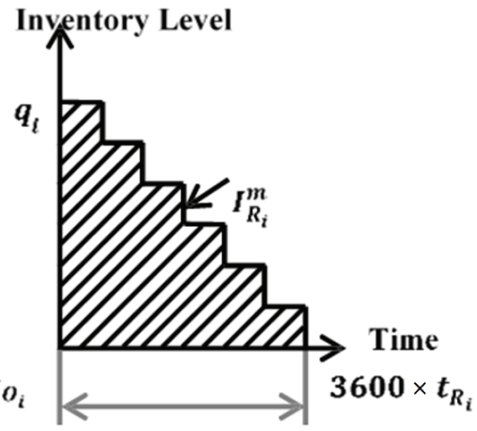

${ }^{T} S_{i}$

Figure 3: Inventory level of market i.

The holding cost of OW (Equation 8) and holding cost of RW (Equation 9), as well as the deteriorating cost (Equation 10) is calculated for one planning horizon. The remaining products in the warehouse are calculated as in Equation 11. 


$$
\begin{gathered}
H C_{O_{i}}=H_{O_{i}}\left(\frac{q_{i} \times 3600 \times t_{R_{i}}+\left(\left[\frac{1}{T_{i}}\right]-1\right) \sum_{m=1}^{q_{i}}\left(I_{O_{i}}^{m} \times t p\right)+\sum_{m=1}^{q_{i}}\left(I_{O_{i}}^{m} \times t p\right)+\sum_{r_{i}+1}^{q_{i}}\left(I_{O_{i}}^{m} \times t p\right)+r_{i} \times t e_{O_{i}}}{3600}\right) \\
H C_{R_{i}}=H_{R_{i}}\left(\frac{\left|\left[\frac{1}{\left.T_{i}\right]}\right]-1\right| \sum_{m=1}^{q_{i}-x_{i} W_{i}}\left(I_{R_{i}}^{m} \times t p\right)+\sum_{r_{i}=1}^{q_{i}-x_{i} W_{i}}\left(I_{R_{i}}^{m} \times t p\right)+r_{i} \times t e_{R_{i}}}{3600}\right) \\
P_{i}\left[\frac{1}{T_{i}}\left(\left[q_{i}\right]-d_{i} T_{i}\right)\right]=P_{i}\left[\frac{\left[q_{i}\right]}{T_{i}}-d_{i}\right] \\
r_{i}=n \times q_{i}-d_{i}-d_{p_{i}}
\end{gathered}
$$

Where, te $\mathrm{O}_{\mathrm{i}}=3600\left(1-t_{R_{i}}\right)-2 \times T_{S_{i}}-\left(q_{i}-r_{i}\right) \times t$ pand te $\mathrm{R}_{\mathrm{i}}=3600-2 \times T_{S_{i}}-\left(q_{i}-r_{i}\right) \times t p$

The theoretical result of the net profit (TR1) is calculated from Equation 1. Since the simulation model has several adjustments to cope with the software limitation, the holding cost and the deterioration cost are calculated. Therefore, the theoretical result of the net profit is adjusted (TR2). The simulation result (SR) of the net profit is calculated using the same formula as the theoretical result (TR2). But, the inventory level is obtained from the average content of the warehouses in the simulation model. The comparison of the net profit can be seen in Table 4. In the validation process, the net profit that is obtained from theoretical result and simulation result have a slight difference. The differences are caused by the rounding of tp in the simulation model. In conclusion, the simulation model can already imitate the proposed method [1]

In the validation process, the net profit that is obtained from theoretical result and simulation result have a slight difference. The differences are caused by the rounding of tp in the simulation model. In conclusion, the simulation model can already imitate the proposed method [1].

\section{Experiment model}

\subsection{Simulation model}

This research uses a textile and apparel company in Taiwan as the study case. The addressed company has two main products, clothes and OBM. Each product needs a different space size for storing. Clothes products occupy the first and second floor of 
TABLE 4: Comparison of net profit

\begin{tabular}{|c|c|c|c|c|c|c|c|c|c|c|c|}
\hline \multicolumn{2}{|l|}{ Market } & 1 & 2 & 3 & 4 & 5 & 6 & 7 & 8 & 9 & 10 \\
\hline \multirow[t]{3}{*}{ Scenario 1} & TR1 & 88484 & 91223 & 80614 & 91532 & 89520 & 85774 & 83608 & 79879 & 87257 & 82307 \\
\hline & TR2 & 88331 & 91443 & 80760 & 91517 & 89481 & 85727 & 83799 & 79884 & 87287 & 82075 \\
\hline & SR & 88330 & 91437 & 80761 & 91508 & 89481 & 85720 & 83799 & 79881 & 87287 & 82072 \\
\hline \multirow{3}{*}{ Scenario 2} & TR1 & 89780 & 90061 & 79717 & 90720 & 91309 & 91348 & 85373 & 80659 & 90157 & 81099 \\
\hline & TR2 & 89769 & 89898 & 79867 & 90708 & 91025 & 91341 & 85252 & 80543 & 90184 & 80854 \\
\hline & SR & 89767 & 89890 & 79868 & 90700 & 91025 & 91333 & 85254 & 80539 & 90184 & 80849 \\
\hline \multirow[t]{3}{*}{ Scenario 3} & TR1 & 90103 & 90061 & 80485 & 89744 & 89032 & 87462 & 84931 & 80270 & 89190 & 80305 \\
\hline & TR2 & 89967 & 90140 & 80492 & 89729 & 88867 & 87428 & 84787 & 80300 & 89218 & 80177 \\
\hline & SR & 89965 & 90135 & 80493 & 89723 & 88867 & 87421 & 84788 & 80298 & 89218 & 80176 \\
\hline \multirow[t]{3}{*}{ Scenario 4} & TR1 & 86380 & 91056 & 81511 & 87956 & 88706 & 85436 & 87580 & 81957 & 88546 & 81906 \\
\hline & TR2 & 86360 & 91026 & 81494 & 87927 & 88516 & 85386 & 87485 & 81826 & 88574 & 81686 \\
\hline & SR & 86359 & 91021 & 81494 & 87922 & 88516 & 85380 & 87486 & 81824 & 88574 & 81684 \\
\hline \multirow[t]{3}{*}{ Scenario 5} & TR1 & 90103 & 91886 & 80357 & 90719 & 89194 & 87800 & 85373 & 79880 & 91123 & 80572 \\
\hline & TR2 & 89826 & 91856 & 80225 & 90835 & 906 & 87768 & 85536 & 79911 & 91151 & 80457 \\
\hline & SR & 89825 & 91847 & 80225 & 90826 & 88905 & 87761 & 85536 & 79909 & 91151 & 80455 \\
\hline
\end{tabular}

the warehouse, and the space allocation is following the company's arrangement. OBM products occupy the third and fourth floor of the warehouse, and the space allocation is following the configuration from the proposed method in Lin and Wang [1]. In the case where the available space in OW are not enough to satisfy the desired configuration, the OBM products that need to utilize the OW will need to compete over the available space. The arrangements are based on the proportion of the product, which calculated as the space that is needed by the product divided by the space that is needed by all of OBM product multiplied by the available space in the OW.

All of the products use the same resources for material handling. Therefore, both clothes product and OBM product will compete over the available resources for the incoming and outgoing process. In which, all of the products are handled based on the first come first served discipline. Two elevators with maximum speed of $1 \mathrm{~m} \mathrm{~s}^{-1}$ (Hydraulic Freight Elevators 2004) will be used to move the product to a different floor in the warehouse. Two forklifts with maximum speed $1 \mathrm{~m} \mathrm{~s}^{-1}$ [16], each in the first and second floor will handle the movement of products in the related floor. There are six operators where three on the third floor and the rest on the fourth floor will handle the movement of products in the related floor. Since the length of pace that is comfortable 
and not too exhausting is about $0.5 \mathrm{~m}$ and $0.75 \mathrm{~m}$ [17] and the operators carry some products, the speed of the operator is assumed $0.5 \mathrm{~m} \mathrm{~s}^{-1}$.

The clothes products have constant demand, while the demand for the OBM products is following a statistical distribution (Table 5). The statistical distribution is used to determine the number of batches. The number of product in one batch is 40 pieces for OBM 1, 10 pieces for OBM 2 and OBM 3, and six pieces for OBM 4 and OBM 5.

Since the clothes demand is assumed to be constant, the replenishment quantity of clothes products are calculated using EOQ method, and the replenishment cycle time is calculated as Demand/EOQ. The setup cost for the clothes is 751.9 per order and the holding cost is 0.5 per piece. The demand for OBM products have variation, and the replenishment quantity, as well as the replenishment cycle time of OBM products, are following the inventory policy from [1].

TABLE 5: Demand for each products

\begin{tabular}{ll} 
Type & Name \\
Clothes (in piece) & Material \\
& Secondary material \\
& Finished products \\
\hline OBM (in piece) & Bed cover \\
\hline Summer quilt \\
Pillow \\
\hline Winter quilt \\
Bed sheet
\end{tabular}

\begin{tabular}{cl} 
Product No & Value \\
\hline 1 & $540 \mathrm{wk}^{-1}$ \\
\hline 2 & $200 \mathrm{wk}^{-1}$ \\
3 & $20 \mathrm{~d}^{-1}$ \\
\hline 1 & $\log _{\text {normal }}\left(93,10^{2}\right) \times 40 \mathrm{mo}^{-1}$ \\
\hline 2 & $\log _{\text {normal }}\left(39,10^{2}\right) \times 10 \mathrm{mo}^{-1}$ \\
\hline 3 & $\log _{\text {normal }}\left(120,10^{2}\right) \times 10 \mathrm{mo}^{-1}$ \\
\hline 4 & $\log _{\text {normal }}\left(1093,10^{2}\right) \times 6 \mathrm{mo}^{-1}$ \\
\hline 5 & $\log _{\text {normal }}\left(115,10^{2}\right) \times 6 \mathrm{mo}^{-1}$
\end{tabular}

The clothes products will be sent to the customer on a weekly or daily basis. The number of products that are sent to the customer is exactly the same as the demand. In condition when the products in the warehouse are not enough to satisfy the demand, backorder is used. It is assumed that the total number of markets that need the OBM products are 10 markets. Therefore, in total there are 50 RWs that are used to store different OBM products for different markets. The OBM products that are stored in RW will be sent to the customer every tp, while the OBM products that are stored in OW will be sent to the customer as soon as the warehouse is replenished (if only OW is used to serve the market demand) or as soon as the inventory level in RW becomes zero (if both OW and RW are used to serve the market demand). Based on the configuration from Lin and Wang [1], there are seven OBM products that will be placed in OW. Products from RW are sent one by one, while products from OW are sent in a batch, and the 
number of quantity in one batch is exactly the same as the demand. Framework of the simulation model can be seen in Figure 4.

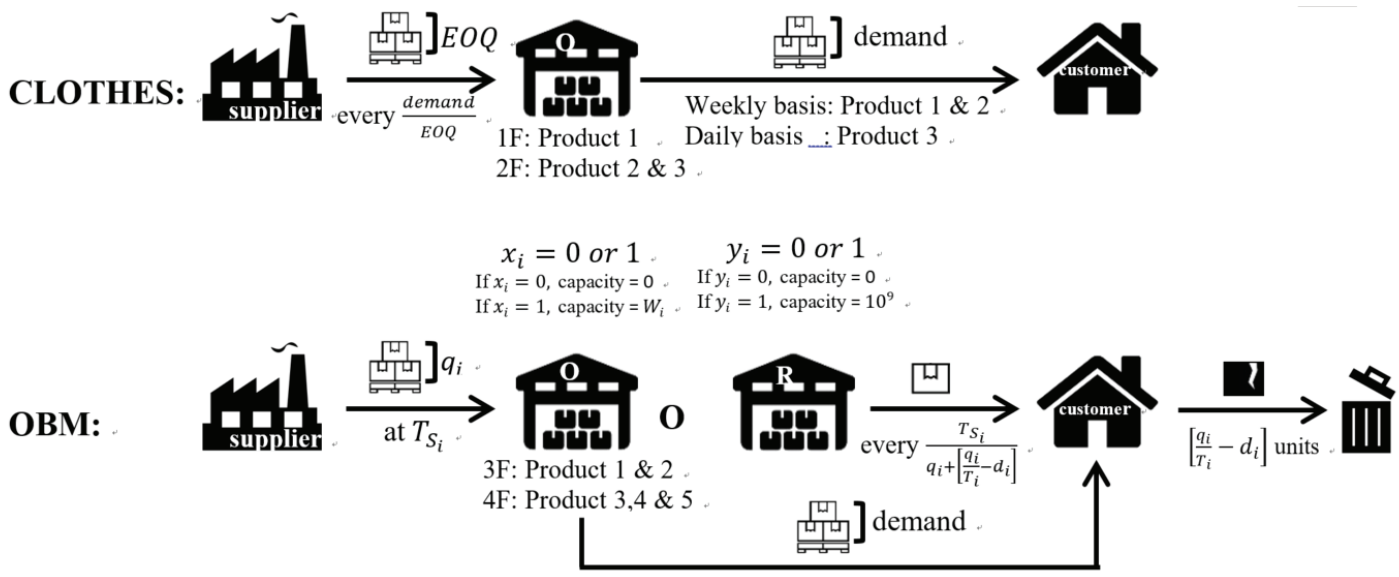

Figure 4: The framework of the simulation model.

The stopping criteria of the simulation are time, in which the simulation will be stopped when the time equals to 1 mo. At the end of the simulation, the net profit will be calculated. The parameter values that are used to calculate the profit can be seen in Table 6.

TABLE 6: Paramater settings

\begin{tabular}{|c|c|c|c|c|c|c|c|c|c|c|}
\hline \multirow[t]{2}{*}{ Parameter } & \multicolumn{10}{|c|}{ Market } \\
\hline & 1 & 2 & 3 & 4 & 5 & 6 & 7 & 8 & 9 & 10 \\
\hline$\rho_{i}$ (/batch) & \multicolumn{10}{|l|}{200} \\
\hline $\mathrm{O}_{i}$ & 541 & 916 & 818 & 679 & 616 & 655 & 998 & 839 & 859 & 598 \\
\hline $\mathrm{H}_{O i}$ (/batch) & 9.3 & 8.5 & 8.9 & 8.8 & 8.4 & 8.4 & 8.8 & 9.3 & 9.0 & 8.4 \\
\hline $\mathrm{H}_{R i}$ (/batch) & 11.9 & 11.3 & 10.9 & 10.8 & 10.3 & 10.8 & 11.8 & 11.0 & 12.0 & 10.3 \\
\hline $\mathrm{P}_{i}$ (/batch) & 107 & 96 & 107 & 102 & 107 & 91 & 109 & 107 & 102 & 107 \\
\hline U (/batch) & \multicolumn{10}{|l|}{40} \\
\hline $\mathrm{B}\left(\mathrm{W}_{i}, \mathrm{~d}_{i}\right)$ & \multicolumn{10}{|c|}{$15 \mathrm{~W}_{i}+10 \mathrm{~d}_{i}$} \\
\hline $\mathrm{R}\left(\mathrm{d}_{i}\right)$ & \multicolumn{10}{|l|}{$10 \mathrm{~d}_{i}$} \\
\hline$B G$ & \multicolumn{10}{|c|}{1500000} \\
\hline
\end{tabular}

\subsection{Statistical analysis}

In Lin and Wang [1], the variation of the demand is always the same and the resources for material handling are ignored. Further, it is assumed that the desired capacity can always be provided in the OW. In the real case problem, the demand may have different 
variation and resources for material handling are needed. Besides, the desired capacity may not be provided in the OW due to limited space.

Therefore, a two-level full factorial design with four factors is conducted to analyze the effects of the parameters mentioned above on the net profit. The factors that are analyzed are demand variation of the OBM product, the space in OW that are available for OBM products, the speed of the elevator, and the operator's capacity in third and fourth floor, as well as the capacity of the forklifts in the first and second floor. Each factor has two levels, low and high (Table 7). Since in the business operation, the company needs to analyze the profit for the long term and the simulation model is designed to stop after 1 mo, for each combination, 30 replications are conducted.

TABLE 7: Levels of the factor

\begin{tabular}{|c|c|c|c|}
\hline & \multirow[t]{2}{*}{ Factor } & \multicolumn{2}{|c|}{ Levels } \\
\hline & & Low (-1) & High (1) \\
\hline Demand & Standard deviation & 5 & 10 \\
\hline \multirow[t]{7}{*}{ Space (in pieces) } & OW313 & 160 & 320 \\
\hline & OW321 & 100 & 200 \\
\hline & OW322 & 65 & 130 \\
\hline & OW436 & 385 & 770 \\
\hline & OW439 & 135 & 270 \\
\hline & OW443 & 1293 & 2586 \\
\hline & OW4510 & 285 & 570 \\
\hline \multirow[t]{2}{*}{ Speed (in $\mathrm{mm} \mathrm{s}^{-1}$ ) } & Elevator2 & 500 & 1000 \\
\hline & Elevator3 & 500 & 1000 \\
\hline \multirow[t]{8}{*}{ Capacity (in pieces) } & Operator31 & 5 & 10 \\
\hline & Operator32 & 5 & 10 \\
\hline & Operator33 & 5 & 10 \\
\hline & Operator41 & 5 & 10 \\
\hline & Operator42 & 5 & 10 \\
\hline & Operator43 & 5 & 10 \\
\hline & Forklift1 & 625 & 1250 \\
\hline & Forklift2 & 150 & 300 \\
\hline
\end{tabular}

The result is analyzed using $\alpha=0.05$. From the ANOVA, it can be seen that the significant main factors are demand variation of the OBM (factor $A$ ), the space in OW that are available for OBM (factor B), the speed of the elevator (factor C), and the capacity of operators and forklifts (factor D). The interaction between factor B and factor 
$D$ is significant, while the other $n$-factor interactions are insignificant. The main effect plot shows that lower demand variation, lower available space in OW, higher speed of elevator, and higher capacity of operators and forklifts will result in higher net profit. If space is low, the lower capacity of operators and forklifts will result in higher net profit. If space is high, the higher capacity of operators and forklifts will result in a higher net profit (Figure 5). The R-square value is $76.97 \%$, which means the factors that are included in the DOE represent $76.97 \%$ of all the variability in the profit (those factors capture more than half of the possible variation in net profit). There may be additional factors that affect the net profit [18]. Since there are some $n$-factor interactions that are insignificant, the ANOVA table is adjusted (Table 8). In which, the in-significant factors are not included in the calculation. The R-square value of the adjusted ANOVA table is $76.75 \%$.

TABLE 8: Revised ANOVA result

\begin{tabular}{|l|c|c|c|c|c|c|c|}
\hline Source & DF & Seq SS & Adj SS & Adj MS & F & P \\
\hline A & 1 & $2.20280 \mathrm{E}+10$ & $2.20280 \mathrm{E}+10$ & $2.20280 \mathrm{E}+10$ & 101.22 & 0 \\
\hline B & 1 & $9.48286 \mathrm{E}+10$ & $9.48286 \mathrm{E}+10$ & $9.48286 \mathrm{E}+10$ & 435.72 & 0 \\
\hline C & 1 & $3.52048 \mathrm{E}+10$ & $3.52048 \mathrm{E}+10$ & $3.52048 \mathrm{E}+10$ & 161.76 & 0 \\
\hline D & 1 & $1.44654 \mathrm{E}+10$ & $1.44654 \mathrm{E}+10$ & $1.44654 \mathrm{E}+10$ & 66.47 & 0 \\
\hline B $^{*} \mathrm{D}$ & 1 & $1.74029 \mathrm{E}+11$ & $1.74029 \mathrm{E}+11$ & $1.74029 \mathrm{E}+11$ & 799.64 & 0 \\
\hline Error & 474 & $1.03159 \mathrm{E}+11$ & $1.03159 \mathrm{E}+11$ & $2.17636 \mathrm{E}+08$ & & \\
\hline Total & 479 & $4.43715 \mathrm{E}+11$ & & & &
\end{tabular}

Since the movement of the products in the OW use the same resources, there are several parameters that can also affect the net profit, such as the operators and forklifts speed, the acceleration and deceleration of the resources, and so on. To build a simulation model that is close to the real case problem, another factor such as demand variation of the clothes product can also be considered. Therefore, besides those four factors mentioned before, several parameters can be added in the DOE to capture more possible variation in the net profit and increase the R-square value.

\section{Conclusion}

This research has developed a simulation model to monitor the real condition in the textile and apparel company when using the proposed method from 0 . The simulation model is created using Flexsim, which is a discrete event simulation software. Therefore, 


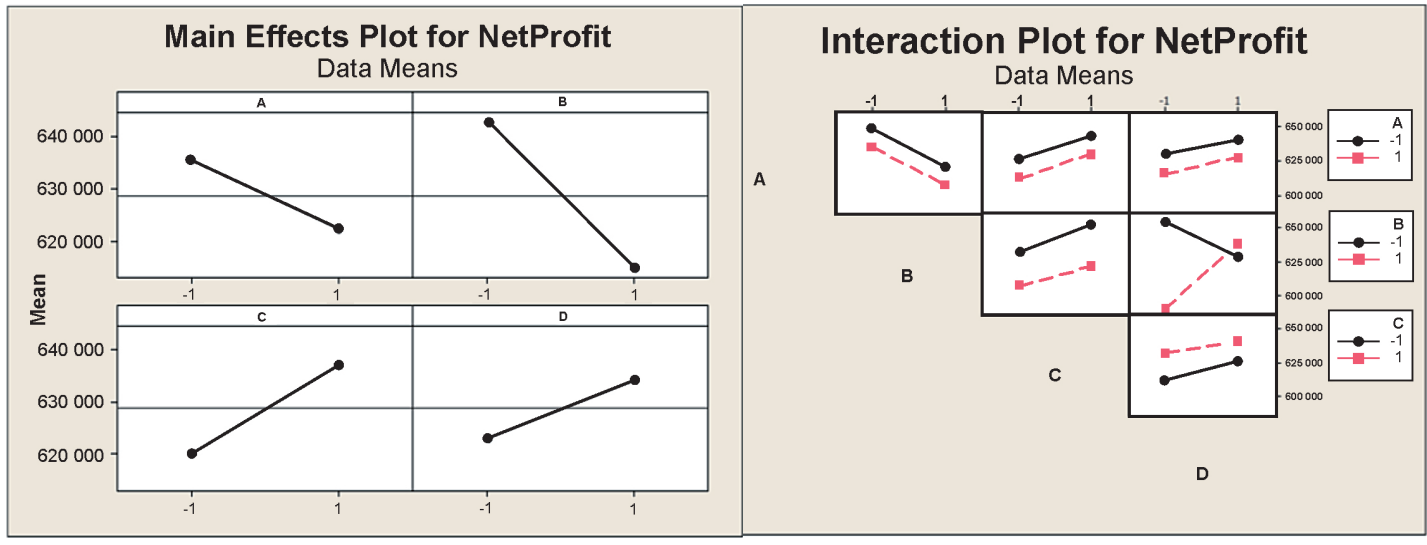

Figure 5: Main effect and interaction plot.

several adjustments are made to cope with software limitation. The incentive policy of the RW is ignored and the products are sent one by one at a specific interval time.

The implementation of the proposed method in the real case problem is analyzed using two-level full factorial design with four factors and 30 replications. The ANOVA results show that all of the main factors are significant. The R-square value is 76.75 $\%$, which means the factors that are included in the DOE represent $76.75 \%$ of all the variability in the profit.

In conclusion, the simulation model can be used to monitor the real condition of the company when implementing the desired warehouse configuration, which has not to be achieved by stochastic optimization models. The net profit when facing different demand possibility can also be obtained.

\section{References}

[1] Lin YS, Wang KJ. A two-stage stochastic optimization model for warehouse configuration and inventory policy of deteriorating items. Computers \& Industrial Engineering 2018; 120:83--93.https://www.sciencedirect.com/science/article/abs/ pii/S036083521830144X

[2] Liao JJ, Chung KJ, Huang KN. A deterministic inventory model for deteriorating items with two warehouses and trade credit in a supply chain system. International Journal of Production Economics 2013; 146(2):557--565. https://www.sciencedirect. com/science/article/pii/S092552731300337X

[3] Hariga MA, Al-ahmari A. An integrated retail space allocation and lot sizinf models under vendor managed inventory and consignment stock arrangements. Computer \& Industrial Engineering 2013; 64(1):45--55. https://www.sciencedirect.com/science/ 
article/abs/pii/S036083521200229X

[4] Fleisch E, Tellkamp C. Inventory inaccuracy and supply chain performance: a simulation study of a retail supply chain. International Journal of Production Economics 2005; 95(3):373--385. https://www.sciencedirect.com/science/article/pii/ S0925527304000386

[5] Huq F, Cutright K, Jones V, Hensler DA. Simulation study of a two-level warehouse inventory replenishment system. International Journal of Physical Distribution and Logistics Management 2006; 36(1):51--65. https://www.emeraldinsight.com/doi/abs/ 10.1108/09600030610642931

[6] Tako AA, Robinson S. The application of discrete event simulation and system dynamics in the logistics and supply chain context. Decision Support Systems 2012; 52(4):802--815. https://www.sciencedirect.com/science/article/pii/ S0167923611002211

[7] Longo F, Mirabelli G. An advanced supply chain management tool based on modeling and simulation. Computers \& Industrial Engineering 2008; 54(3):570--588. https://www.sciencedirect.com/science/article/abs/pii/S0360835207002100

[8] Ramanathan U. Performance of supply chain collaboration -- A simulation study. Expert Systems with Applications 2014; 41(1):210--220. https://www.sciencedirect. com/science/article/pii/S0957417413004995

[9] Yu JCP, Wang KJ, Lin YS. Managing dual warehouses with an incentive policy for deteriorating items. International Journal of Systems Science 2016; 47(3):586--602. https://www.tandfonline.com/doi/abs/10.1080/00207721.2014.891673

[10] Reddon T. (2018) Six facts about forklifts [Online] from https://thejournal.mheda.org/ 2013/03/06/facts-about-forklifts/ (2018). [Accessed on 20 January 2017] 